\title{
RISK OF TRAVELING BY PLANE IN PATIENTS WITH RESPIRATORY SYSTEM DISEASE
}

\section{RIZIK OD PUTOVANJA AVIONOM BOLESNIKA SA OBOLJENJIMA RESPIRATORNOG SISTEMA}

\author{
Dragica Pešut ${ }^{1,2}$, Ljudmila Nagorni Obradović, ${ }^{1,2}$, Vladimir Žugić, ${ }^{1,2}$, Marina Roksandić Milenković, ${ }^{1,2}$, Branislava Milenković1,2
}

\begin{abstract}
Summary
In an attempt to meet desires and needs of the patients with pulmonary diseases who plan to travel by air craft, physicians might face complex problems. They are expected to estimate individual risk and need of oxygen supplementation that might be neccessary. Sometimes, these patients are a source of infection to other passengers. Some international air travel guidelines offer precise and mandatory conditions, which should be fulfilled during the flight in case such a patient has to travel. Thus, patients with drug resistant tuberculosis are not permitted to travel at all, while all the other patients with pulmonary tuberculosis and other air born infections should not travel during the infectious period. Recent or uncured pneumothorax and hemoptisis are contraindications for travelling. Other patients with pulmonary diseases, especially those with manifested respiratory insufficiency should respect the rules, which include contacting air travel company prior to flight, sharing information about their health conditon and asking for details on possibilities of oxygen supplementation while on board, currence voltage, and availability of plugs in the cabin where the devices for respiratory support might be put in, etc. A possibility of hypoxia during the flight is an important individual risk. Methods of hypoxia prediction and possibilities of oxygen supplementation in air craft cabin are in focus of current research.
\end{abstract}

Key words: respiratory system; disease; travel; air craft; high altitude; risk; regulation, oxygen.

\section{Sažetak}

U odgovoru na želje i potebe plućnih bolesnika za putovanjem avionom, lekari se katkad susreću sa kompleksnim problemima. Od njih se očekuje da procene individualni rizik i potrebu za obezbeđivanjem nadoknade kiseonika ovim bolesnicima. Neke od međunarodnih smernica iz oblasti vazduhoplovnog saobraćaja preciziraju uslove putovanja za obolele. Katkad ovi bolesnici predstavljaju izvor zaraze za druge putnike. Tako, nije dozvoljeno putovanje obolelima od rezistentne tuberkuloze, odnosno, svim obolelima od tuberkuloze i drugih zaraznih respiratornih bolesti u periodu zaraznosti. Apsolutno je kontraindikovano putovanje obolelima od skorašnjeg ili nesaniranog pneumotoraksa i onima sa hemoptizijama. Ostali plućni bolesnici, a naročito oni sa već ispoljenom respiracijskom insuficijencijom treba da se pridržavaju pravila koja podrazumevaju stupanje u vezu sa aviokompanijom pre leta, obaveštavanje o svom zdravstvenom stanju i informisanje o mogućnostima nadoknade kiseonika tokom leta, naponu struje i priključcima u letilici gde bi aparat za potporu disanja tokom putovanja trebalo da bude priključen i drugo. Kako se značajan individualni rizik pri letu avionom svodi na mogućnost nastanka hipoksije, poseban deo istraživanja u ovoj oblasti posvećen je savremenim metodama predviđanja hipoksije i mogućnostima nadoknade kiseonika tokom boravka u avionskoj kabini.

Ključne reči: respiratorni sistem; bolest; putovanje; avion; velika nadmorska visina; rizik; propisi; kiseonik

\section{UvoD}

Oko 2,75 milijarde ljudi u svetu godišnje koristi avionski saobraćaj kao najbrži vid prevoza (1). Produženje životnog veka, bolja prosvećenost ljudi i sve veća dostupnost avionskog saobraćaja, povećali su broj putnika starijeg životnog doba, a samim tim i putnika sa različitim hroničnim bolestima. Među njima, sve češći su i putnici oboleli od različitih bolesti respiratornog sistema, pa i oni koji koriste dugotrajnu oksigenoterapiju (DOT)(2). Uslovi koji vladaju u avionskoj kabini tokom leta, mogu da utiču na zdavstveno stanje ovih bolesnika. Zbog izmenjene fiziologije disanja na velikoj nadmorskoj visini, uobičajena adaptacija, kakva postoji kod zdravih osoba, nekada nije dovoljna kod onih koji već imaju respiracijsku insuficijenciju ili su pod rizikom da je razviju.
Razmatranje značaja procene rizika za putovanje avionom plućnih bolesnika koje sledi ne obuhvata vazdušni medicinski transport bolesnika, koji se, obično, izvodi helikopterima za tu namenu na nadmorskoj visini koja je neuporedivo manja u odnosu na visinu na kojoj se odvija vazduhoplovni saobraćaj komercijalnim letovima. Dok helikopter za medicinski transport obično ne prelazi visinu od oko $1500 \mathrm{~m}$, komercijalni avionski saobraćaj se odvija na visinama koje mogu veoma da variraju od 8000 -10000 m i više. Zato za medicinski transport helikopterom, praktično, nema kontraindikacija a rizik od putovanja avionom na komercijalnim letovima, koje zahteva adaptaciju organizma usled pritiska u avionskoj kabini (ekvivalentan barometarskom pritisku na visini od oko 1800 - $2400 \mathrm{~m}$ nadmorske visine pa i ve- 
ćem), treba da se razmotri u svakom pojedinom slučaju (3). Najčešće bolesnici sa hroničnim plućnim bolestima kao što su hronična opstruktivna bolest pluća (HOBP), bronhiektazije i druge, pitaju lekare da li je putovanje avionom bezbedno za njih. Ukoliko već imaju respiracisjku insuficijenciju, strepe da bi putovanje avionom moglo dodatno da pogorša njihovo zdravstveno stanje. I zaista, ukoliko pilot proceni da je neophodno, maksimalno povećanje visine leta može da bude toliko da pritisak u kabini ogovara onom na nadmorskoj visini od $3000 \mathrm{~m}$. Tada pogotovu, efikasnost aktiviranih adaptacionih mehanizama kod bolesnika sa oboljenjima respiratornog sistema može da bude nedovoljna.

Kako se značajan individualni rizik pri letu avionom svodi na mogućnost nastanka hipoksemije i sledstvene hipoksije, poseban deo istraživanja u ovoj oblasti posvećen je savremenim metodama predviđanja ovih stanja i mogućnostima nadoknade kiseonika tokom boravka u avionskoj kabini. Katkada oboleli može da predstavlja izvor zaraze za druge putnike u kabini (4-6). Postupak sa ovakvim bolesnicima kao i ukupne mere predostrožnosti pre planiranog putovanja avionom bolesnika sa oboljenima respiratornog sistema, kao i postupci posle putovanja, regulisani su propisima (4).

\section{FiziologiJA disANJA NA VELIKOJ NADMORSKOJ VISINI}

Pod velikom nadmorskom visinom uglavnom se podrazumevaju mesta iznad $3000 \mathrm{~m}$, a pod ekstremno velikom nadmorskom visinom mesta iznad $6000 \mathrm{~m}$. Fiziologija disanja na tim visinama prolazi kroz adaptacione promene koje se nazivaju aklimatizacija. Osnovni uzrok potrebe za aklimatizacijom je hipoksemija izazvana smanjenim parcijalnim pritiskom kiseonika u vazduhu $\left(\mathrm{P}_{\mathrm{A}} \mathrm{O}_{2}\right)$, što je posledica pada atmosferskog pritiska sa povećanjem visine. Iako se koncentracija kiseonika u atmosferskom vazduhu ne smanjuje sa povećanjem nadmorske visine, parcijalni pritisak kiseonika se smanjuje zbog smanjenja atmosferskog pritiska (7), ali i povećanja parcijalnog pritiska vodene pare u vazduhu (sa $6 \%$ na nivou mora na $19 \%$ na ekstremno visokim nadmorskim visinama).

Osnovni odgovor organizma na smanjeni $\mathrm{P}_{\mathrm{A}} \mathrm{O}_{2}$ je hiperventilacija zbog stimulacije perifernih hemoreceptora, posebno u karotidnim telima (8). Hiperventilacija, sa svoje strane, dovodi do hipokapnije i respiratorne alkaloze, koja se ubrzo koriguje povećanom ekskrecijom bikarbonata bubrezima. Akutni odgovor na hipoksemiju velikih visina je značajan porast ventilacije tek kada parcijalni pritisak kiseonika u arterijskoj $\operatorname{krvi}\left(\mathrm{PaO}_{2}\right)$ padne ispod $7 \mathrm{kPa}$. Nije jasan mehanizam ovakvog usporenog odgovora ventilacije na akutnu hipoksemiju izazvanu padom parcijalnog pritiska kiseonika $\mathrm{u}$ atmosferskom vazduhu. Mogući mehanizam je hipoksemijom stimulisano povećanje cirkulacije likvora, što sa svoje strane dovodi do smanjena ekstracelularnog parcijalnog pritiska ugljen-dioksida $\left(\mathrm{PCO}_{2}\right)$ u mozgu i smanjenja $\mathrm{pH}$ oko hemoreceptora u produženoj moždini. Posle aklimatizacije, ventilacija je značajno povećana i pri normalnim vrednostima $\left(\mathrm{PaO}_{2}\right)$. Na velikim nadmorskim visinama dolazi i do značajno povećanog ventilatornog odgovora na hiperkapniju. Naime, i normalne vrednosti $\mathrm{PCO}_{2}$ na nivou mora dovode do značajne stimulacije ventilacije (9). Mehanizam ventilatornog odgovora na $\mathrm{PCO}_{2}$ pri velikim nadmorskim visinama je, takođe nejasan, ali se pretpostavlja da se radi o homeostatskom podešavanju ekstracelularnog $\mathrm{pH}$ u mozgu, verovatno usled povećane ekskrecije bikarbonata bubrezima, aktivnog transporta bikarbonata i povećane sekrecije mlečne kiseline.

Smanjeni parcijalni pritisak kiseonika u vazduhu, kao i povećan parcijalni pritisak vodene pare dovode do smanjenog parcijalnog pritiska kiseonika u alveolama. Tako je alveolarni $\mathrm{P}_{\mathrm{A}} \mathrm{O}_{2}$ na oko $6000 \mathrm{~m}$ nadmorske visine oko 6-7 kPa, naspram 12-13 kPa na nivou mora (10). S obzirom na to da je difuzija kiseonika u plućima direktno proporcionalna gradijentu parcijalnog pritiska kiseonika između alveola i plućnih kapilara (gradijent $\mathrm{P}_{\mathrm{A}} \mathrm{O}_{2}-\mathrm{P}_{\mathrm{a}} \mathrm{O}_{2}$ ), jasno je da je i difuzija na velikim nadmorskim visinama značajno smanjena, prvenstveno pri naporu, a na ekstremno velikim nadmorskim visinama i u miru. Drugi faktori od kojih zavisi difuzija kiseonika u plućima su praktično nepromenjeni na bilo kojoj nadmorskoj visini (11).

$\mathrm{Na}$ velikim nadmorskim visinama dolazi do blagog smanjenja vitalnog kapaciteta $\mathrm{zbog}$, takođe, blagog slabljenja snage respiracijske muskulature, dok protoci kroz disajne puteve nisu smanjeni i pored slabosti respiratorne pumpe zahvaljujući smanjenju gustine vazduha.

Kardiovaskularni odgovor na veliku nadmorsku visinu je plućna vazokonstrikcija izazvana hipoksemijom i hipoksijom tkiva. Plućna vazokonstrikcija, zajedno sa refleksnom tahikardijom i povećanim sistolnim volumenom, dovodi do prolazne plućne hipertenzije koja retko ima klinički značaj, ali može da se manifestuje pri većoj fizičkoj aktivnosti neaklimatizovanih osoba.

Svi navedeni mehanizmi u roku od nekoliko dana dovode do aklimatizacije osobe koja živi na nižim nadmorskim visinama. Međutim, u određenom, ne tako malom broju slučajeva, dolazi do akutnih poremećaja zdravstvenog stanja kod onih osoba koje nisu aklimatizovane. U te poremećaje spadaju akutna visinska bolest i njen teži oblik akutni edem mozga, kao i akutni plućni edem. 
Akutna planinska bolest (eng. acute mountain sickness - AMS) predstavlja poremećaj zdravstvenog stanja prilikom naglog penjanja na velike nadmorske visine, obično posle 6-12 sati. AMS je posledica akutne hipoksemije i akutnog blagog edema mozga i manifestuje se glavoboljom, mučninom, malaksalošću, povraćanjem i nesanicom. Teži oblik AMS naziva se edem mozga velikih visina (eng. high-altitude cerebral edema - HACE) i manifestuje se akutnim težim poremećajem svesti, sve do razvoja kome. U najtežim slučajevima dolazi i do smrtnog ishoda zbog hernijacije mozga. Patogoneza nije sasvim jasna, ali se pretpostavlja da se radi o povećanoj cirkulaciji likvora zajedno sa poremećajem distribucije tečnosti usled hipersekrecije aldosterona i antidiuretskog hormona (12). Lečenje se sastoji od hitne primene kiseonika, hitnog spuštanja na niže nadmorske visine, primene acetazolamida i deksazona.

\section{NeKARDiogeni PLUĆNI EDEM}

Nekardiogeni plućni edem (eng. high-altitude pulmonary edema - HAPE) nastaje zbog izražene i neravnomerno raspoređene plućne vazokonstrikcije sa posledičnom hiperperfuzijom delova pluća koja nisu zaštićena vazokonstrikcijom. Povećan plućni kapilarni pritisak dovodi do eksudacije tečnosti u alveolarne prostore i nastanka edema (13). Klinički, u blažim oblicima, manifestuje se suvim kašljem i dispnejom pri uobičajenom naporu, a u težim, dispnejom u miru, iskašljavanjem ružičastog sputuma, tahikardijom i cijanozom. Na radiografiji toraksa tipičan je izgled zastojnih promena u plućnom parenhimu uz normalnu veličinu srčane senke. U većini slučajeva, primena kiseonika i spuštanje na niže nadmorske visine dovoljni su za izlečenje HAPE. U težim slučajevima, primena nifedipina, uz prethodno navedene mere, dovodi do smanjenja plućnog edema. Diuretici i morfin nisu efikasni.

\section{Kontraindikacije Za PUTOVANJE AVIONOM, SMERNICE I MEĐUNARODNI PROPISI}

Iz navedenih razloga, putovanje avionom obolelih od bolesti respiratornog sistema može da predstavlja rizik od pogoršanja postojećeg stanja ili rizik po život bolesnika. Zato je apsolutno kontraindikovano putovanje obolelima od nesaniranog ili skorašnjeg pneumotoraksa, bilo da se radi o spontanom pneumotoraksu ili onom iza hirurške intervencije i drugih stanja. Osim u retkim izuzecima, ovi bolesnici ne be smeli da putuju avionom pre učinjene drenaže i reekspanzije pluća. Ukoliko je prošlo nedelju dana od stabilizovane reekspanzije pluća dokazane radiografski, putovanje može da se ostvari bez opasnosti $(3,14)$. Međutim, ukoliko postoji utvrđena plućna bolest u osnovi pneumotorak- sa, rizik od ponovnog pneumotoraksa je veći ukoliko osoba putuje avionom. Ovaj rizik se održava narednih godinu dana od pneumotoraksa (15).

Rizik po život bolesnika, odnosno, opasnost od pogoršanja stanja postoji i kod bolesnika sa hemoptizijama, a u svakom slučaju i kod onih bolesnika koji imaju potrebu za kiseoničnom terapijom od $41 / \mathrm{min}$ i više na nivou mora. Za ostale bolesnike sa hroničnim plućnim bolestima važi pravilo da se putovanje odlaže u slučaju egzacerbacije bolesti, pre putovanja ulože svi napori ka poboljšanju stanja i popravljanju eventualne postojeće hipoksemije uz procenu rizika od nastanka hipoksemije za vreme putovanja na velikoj nadmorskoj visini.

\section{PUTNICI KAO IZVOR RESPIRATORNE INFEKCIJE}

Bolesnici koji mogu da predstavljaju izvor zaraze za druge putnike, ne treba da putuju u fazi zaraznosti. Transmisija zaraznih bolesti koje se prenose putem vazduha među ljudima koji borave u zatvorenom prostoru kakve su avionske kabine, uvek je bila poseban predmet interesovanja zdravstvenih radnika i javnosti uopšte, posebno u sezoni godišnjih odmora i putovanja do udaljenih odredišta. Od početka 1990-ih godina do danas, veliku pažnju su izazvale tuberkuloza i, posebno, SARS (eng. Severe Acute Respiratory Syndrome, teški akutni respiratorni sindrom) 2003, jer se radilo o smrtonosnoj bolesti nepoznatog uzroka (6).

Rizik od zaraze zavisi od koncentracije infektivnog agensa u vazduhu, dužini izloženosti izvoru zaraze i individualne prijemčivosti za bolest (16). Rizik od prenošenja infekcije vazduhom pri boravku u avionskoj kabini je veoma mali i ograničen je na one putnike koji su bili u sasvim bliskom kontaktu sa obolelim ili/i bližem kontaktu: putnici u istom redu ili dva reda ispred i iza reda u kojem je zarazni bolesnik $(4,6,17)$. U slučaju da poletanje kasni više od 30 minuta, neophodno je da se obezbedi adekvatna ventilacija radi smanjenja koncentracije potencijalnih zaraznih jezgara u vazduhu. Ovo je regulisano međunarodnim pravilnikom (4). Nema dokaza da recirkulacija vazduha u kabini olakšava prenošenje zaraze.

\section{MeĐunarodne SMernice}

Oboleli od plućne tuberkulozu (zarazni) ne treba da putuju na redovnim linijama putničkog saobraćaja dok ne prođe najmanje dve nedelje propisne terapije antituberkuloticima. Oni koji imaju multirezistentnu tuberkulozu ne treba da putuju dok se ne dokaže da nisu zarazni (negativnim rezultatom kulture sputuma), što može da znači znatno odlaganje putovanja (4). Do sada je zaraza bacilom tuberkuloze dokazana samo na letovima koji su trajali duže od osam sati. Poznavanje regionalne i 
globalne epidemiologije plućnih bolesti koje se prenose respiratornim putem veoma je važno. Međunarodne smernice SZO o zdravlju i međunarodnim letovima ukazuje na mnoge od mikrobioloških uzročnika respiratornih infekcija, njihovu geografsku distribuciju i rizik od prenošenja u zavisnosti i od obavezne imunizacije koja se izvodi u pojedinim zemljama. Tako su pod rizikom od zaraze bakterijom Haemophilus influenzae type $b(\mathrm{Hib})$ pri putovanju avionom nevakcinisana deca a naročito ona starosti do pet godina. Poznato je da ova bakterija godišnje izazove 7-8 miliona slučajeva pneumonije i meningitisa sa stotinama hiljada smrtnih ishoda, uglavnom u zemljama u razvoju, dok je bolest, praktično, iskorenjena u zemljama u kojima se vakcinacija Hib kod dece sprovodi (4).

Neke od međunarodnih smernica iz oblasti vazduhoplovnog saobraćaja preciziraju uslove putovanja za obolele. Tako, nije dozvoljeno putovanje obolelima od rezistentne tuberkuloze, a svim obolelima od plućne tuberkuloze u periodu zaraznosti $(4,6)$. Svi ostali plućni bolesnici a naročito oni sa respiracijskom insuficijencijom treba da se pridržavaju pravila koja podrazumevaju stupanje u vezu sa aviokompanijom pre leta, obaveštavanje o svom zdravstvenom stanju i informisanje o mogućnostima nadoknade kiseonika tokom leta, naponu struje u priključcima letilice gde bi aparat za potporu disanja tokom putovanja trebalo da bude priključen i drugo.

\section{Metode Za PREDViĐANJe HipoKsije}

Da bi se procenio rizik od hipoksije kod bolesnika sa bolestima respiratornog sistema, osmišljene su različite metode za predviđanje hipoksije. Jedna od njih je udisanje hipoksične smeše gasova, a naziva se "hipoksični izazov". Tokom izvo]enja ovog testa, imitira se vrednost parcijalnog pritiska kiseonika u arterijskoj krvi $\left(\mathrm{P}_{\mathrm{a}} \mathrm{O}_{2}\right)$ prilikom putovanja avionom (18). Druga mogućnost ispitivanja je korišćenje hipobaričnih komora, ali se one, uglavnom, ne koriste za rutinsku procenu kod bolesnika, već češće u istraživačke svrhe. Nedostatak ove metode je što su komore glomazne i što bolesnici u njima mogu da dobiju klaustrofobiju. Ispitivanja, sprovedena i kod zdravih osoba i kod bolesnika sa stabilnim stanjem hronične opstruktivne bolesti pluća (HOBP), pokazala su da nije bilo razlika u rezultatima za predviđanje hipoksije između metode udisanja hipoksične smeše i metode hipobarične komore (19).

$\mathrm{Na}$ osnovu sprovedene meta-analize publikovanih radova u vezi sa različitim metodama za predviđanje hipoksije, donesena je preporuka da se kod bolesnika sa stabilnim stanjem HOBP u ispitivanje uključi merenje forsiranog ekspiratornog volumena $u$ prvoj sekundi $\left(\mathrm{FEV}_{1}\right)$ kao i $\mathrm{P}_{\mathrm{a}} \mathrm{O}_{2}$ na nivou zemlje (20).
$\mathrm{U}$ većini studija su za merenje $\mathrm{P}_{\mathrm{a}} \mathrm{O}_{2}$ analizovani gasovi $\mathrm{u}$ arterijskoj krvi i na taj način posmatran stepen nedostatka kiseonika. Analiza kiseonika u arterijskok krvi jeste zlatni standard za određivanje hipoksemije, ali se ovaj postupak svrstava u grupu agresivnih ispitivanja. Takođe, metoda je zahtevna jer podrazumeva analizu neposredno posle uzimanja uzorka krvi. Zato se korišćenje pulsnog oksimetra za procenu nedostatka kiseonika u krvi preporučuje kao jednostavnija metoda koja nije agresivna i koja bi mogla da bude alternativa gasnim analizama arterijske krvi.

Bolesnici lekarima postavljaju i pitanja da li dužina leta može da utiče na pojavu zdravstvenih tegoba usled hipoksije. Većina hipoksičnih izazova se koristila za kliničku procenu bolesnika dok putuju avionom u trajanju od oko 30 minuta jer se pretpostavljalo da je to vreme dovoljno za fiziološke promene koje bi mogle da se dese u organizmu. Tako je ispitivana pojava hipoksije kod bolesnika sa cističnom fibrozom na niskoj nadmorskoj visini $(530 \mathrm{~m})$ kao i posle 7 sati leta avionom na većoj nadmorskoj visini $(2650 \mathrm{~m})(21)$. Izmerene vrednosti su pokazale blagi stepen hipoksije ali nije uočeno pogoršanje tokom produženja vremena putovanja. Jedna druga studija je, pak pokazala da je dužina leta važan faktor koji treba da se uzme u obzir, a pojava mogućih respiratornih simptoma je povezana sa letovima koji su trajali preko tri sata $(2,22)$. Većina upozoravajućih podataka u vezi sa mogućom hipoksijom tokom putovanja avionom odnose se na bolesnike sa HOBP. Inače, s obzirom na visoku prevalenciju ove bolesti, oboleli od HOBP spadaju u najčešće putnike avionom u odnosu na sve druge plućne bolesnike (18).

Savetuje se da bolesnici koji imaju težak oblik plućne bolesti a ne koriste kiseoničnu terapiju prođu testove za procenjivanje hipoksije. Ukoliko se ispolje simptomi hipoksije tokom testiranja, preporučuje se kiseonična potpora u toku leta avionom. Ispitivanja su potvrdila da i oni bolesnici koji imaju rizik od pojave hipoksije tokom leta takođe mogu da putuju avionom uz dodavanje kiseonika. Oni koji nemaju simptome tokom testa procene hipoksije, mogu da putuju bez kiseonika, ali, ukoliko je moguće, stalnim praćenjem stepena hipoksije tokom leta ili pripravnosti za korišćenje kiseoničnog uređaja (2).

Potrebna su dalja istraživanja $\mathrm{u}$ oblasti sprovođenja metoda za predviđanje hipoksije tokom putovanja avionom kako bi se što pouzdanije predvidelo koji bolesnici će razviti simptome ili će imati akutno pogoršanje zbog hipoksije u toku leta avionom (22-25). Iako se smatra da je putovanje avionom za većinu osoba sa hroničnim plućnim bolestima bezbedno, uvek treba biti na oprezu, pogotovu kada su u pitanju bolesnici sa HOBP. Jedna studija je pokazala da je, i pored prethodnog testiranja koje nije ukazalo na rizik od hipoksemije, u $18 \%$ bole- 
snika došlo do pojave simptoma od strane respiratornog sistema tokom leta (26).

\section{NADOKNADA KISEONIKA ZA VREME LETA AVIONOM}

Smanjenje pritiska u avionskim kabinama može da izazove hipoksemiju i pogoršanje dispneje kod bolesnika sa hroničnim plućnim obolenjima. Kod najbrojnijih među njima - onima sa HOBP, jedna četvrtina ima pogoršanje dispneje tokom leta avionom (27). Kod njih je rizik od doživljavanja dispneje u toku leta skoro sedam puta veći nego u kontrolnoj grupi osoba koje nemaju HOBP. Takođe, desaturacija kiseonikom zapažena tokom šestominutnog testa hodanjem (eng. skraćenica 6MWT) su povezane sa intenzitetom simptoma tokom leta. Za procenu parcijalnog pritiska kiseonika kod bolesnika sa HOBP i potrebe za kiseonikom kod ovih bolesnika, mogu da se koriste pomenuti testovi za predviđanje hipoksije (27-30). Tako, kod bolesnika sa stabilnom HOBP bez posledične respiracijske insuficijencije, ne postoje kontraindikacije za putovanje komercijalnim letovima. Međutim, može da se pretpostavi da će za vreme leta bolesnici sa dispnejom i hipoksemijom, a oboleli od HOBP i drugih hroničnih plućnih bolesti, imati manje simptoma ukoliko koriste dopunski kiseonik. Kod odraslih plućnih bolesnika kod koji je $\mathrm{PaO}_{2} \mathrm{u}$ arterijskoj krvi pre putovanja avionom niži od $70 \mathrm{mmHg}$ ili je saturacija kiseonikom niža od $92 \%$, neophodna je primena oksigenoterapije tokom leta (31). Ovim bolesnicima se savetuje da put avionom planiraju 60 dana unapred. Mnoge aviokompanije nude posebne brošure za informisanje putnika sa različitim fizičkim i mentalnim zdravstvenim problemima. Ipak, radi optimalne pomoći, neophodno je individualno savetovanje bolesnika koji imaju plućno oboljenje, a planiraju putovanje avionom. Ukoliko bolesnik ima poremećaj ventilacije, potrebno je da se obezbedi dodatna jedinica kiseonika (portabilni oksigenokoncentrator - POK, POC, eng) koja treba da, preko nosne kanile, obezbedi do 5 litara kiseonika u minuti (najčešći preporučeni protok kiseonika je $2 \mathrm{l} / \mathrm{min}$ ). Kiseonik ne bi trebalo da se koristi tokom uzletanja i sletanja aviona, već kada avion dostigne planiranu visinu leta $(3,28,29)$.

Većina aviokompanija omogućuje korišćenje POK tokom leta, odobrenog za upotrebu uz poštovanje standardnih zahteva i procedura. Putnik mora da dostavi izveštaj lekara o potrebi i načinu korišćenja kiseonika tokom leta. Takođe, POK mora da ima sopstvenu bateriju koja traje $150 \%$ vremena planiranog trajanja leta. Neke kompanije ne dozvoljavaju unošenje POK-a u avionsku kabinu, već same, na zahtev bolesnika-putnika, obezbeđuju kiseoničku potporu tokom puta. Idealno bi bilo da se tokom oksigenoterapije koristi pulsni oksimetar i tako proverava postignuta saturacija krvi kiseonikom. Takođe, kada je neophodno, mogu da se koristite i uređaji sa kontinuiranim pozitivnim pritiskom, ukoliko na taj način može da se postigne zadovoljavajuća ok- sigenacija putnika $(3,28)$. Svi navedeni uređaji moraju da budu odobreni od strane aviokompanije kojoj treba da se prijavi putnik sa plućnom bolešću najmanje 48 sati pre leta. Neke aviokompanije nude posebne opcije prevoza, na primer, rezervaciju dodatnih sedišta ako je potrebno posebno smeštanje putnika.

Porast broja osoba koje imaju hroničnu plućnu bolest sa hipoksemijom, a koje planiraju putovanja avionom, doveo je do interesovanja za pronalaženje novih načina pružanja oksigenoterapije, kao i novih modela koncentratora i drugih uređaja.

\section{LEKAR KAO PUTNIK}

Lekari često putuju avionom: od svih medicinskih nezgoda, koje su prijavljene tokom putovanja, u $85 \%$ slučajeva nalazio se lekar u avionu kao putnik. Skorašnje istraživanje je pokazalo da su najčešća medicinska hitna stanja tokom leta avionom sinkopa, respiratorni i gastrointestinalni simptomi i potvrdilo da je lekar kao putnik često u situaciji da volonterski interveniše (33). Danas članovi posade imaju duže pripreme iz prve pomoći i u stanju su da pomognu ugroženim putnicima više nego ranije. Iako su lekari koji pruže pomoć bolesnom ili povređenom putniku obično zaštićeni od sudskog gonjenja zakonom "dobrog Samarićanina”, trebalo bi da izbegavaju praksu van one za koju su obučeni, odnosno, stručni. Stoga su prethodne pripreme bolesnika sa respiratornim oboljenjima i procena rizika od pogoršanja ukoliko putuju avionom posebno korisne u sprečavanju neželjenih događaja tokom leta i smanjenju broja potrebnih intervencija u avionskoj kabini.

\section{ZAKLJUČAK}

U proceni rizika za putovanje avionom bolesnika sa oboljenima respiratornog sistema, neophodan je individualni pristup i uvid u stvarno stanje bolesti, trajanje putovanja i odredište, procena adaptacionih mehanizama bolesnika na velikoj nadmorskoj visini i rizika od hipoksije, mogućnosti kontrole i lečenja tokom leta, kao i dostupnosti medicinskog kiseonika u kabini. Neophodno je znanje lekara o apsolutnim kontraindikacijama za putovanje avionom bolesnika sa oboljenjima respiratornog sistema, a posebna pažnja treba da se usmeri na one bolesti i stanja u kojima ekspanzija gasa može da izazove bol ili oštećenje tkiva i organa. Poštovanje propisa u pogedu putovanja obolelih od zaraznih i potencijalno zaraznih plućnih bolesti je od velike važnosti iz aspekta prevencije bolesti, pa sve aviokompanije treba da ih se pridržavaju. Činjenica je da milioni ljudi putuju avionom svake godine i da ne mogu svi da budu pregledani zbog rizika po druge putnike koji, eventualno, nose. Međutim, oni koji već znaju da imaju zaraznu bolest, ne treba da putuju, a to nekada znači i znatno odlaganje putovanja. $\mathrm{O}$ tome lekari treba upoznaju bolesnike. 


\section{NAPOMENA}

Rad je usmeno izložen na mini simpozijumu Procena rizika od putovanja avionom kod bolesnika sa respi- ratornim oboljenjima na 43. simpozijumu Stremljenja $i$ novine u medicini, Medicinski fakultet u Beogradu, 12.12.2014.

\section{Literatura}

1. Worldbank. Air transport, passengers carried. 2014 Dostupno na web site adresi: http://data.worldbank.org/indicator/IS.AIR.PSGR.

2. Coker RK, Shiner RJ, Partridge MR. Is air travel safe for those with lung disease? Eur Respir J 2007;30:1057-1063.

3. Ahmedzai S, Balfour-Lynn IM, Bewick T, Buchdahl R, Coker RK, Cummin AR, et al. Managing passengers with stable respiratory disease planning air travel: British thoracic society recommendations. Thorax 2011;66 Suppl 1:i1-30.

4. WHO. International travel and health 2012. Geneva: WHO; Dostupno na web sajt adresi: http://www.who.int/ith

5. WHO. Tuberculosis and air travel. Guidelines for prevention and control. 3rd ed. Geneva: WHO; 2008.

6. Pešut D. Rizik od tuberkuloze za vreme leta avionom. Vojnosanit Pregl 2007; 64(8):511-512.

7. West JB, Lahiri S, Maret KH, Peters RM Jr, Pizzo CJ. Barometric pressures at extreme altitudes on Mt. Everest. J Appl Physiol 1983; 54: $1188-1194$

8. Wolff CB, The control of ventilation in hypoxia, I. International Society of Mountain Medicine Newsletter, 1998; 8(1): 3-6.

9. Kellog $\mathrm{RH}$. The rôle of $\mathrm{CO} 2$ in altitude acclimatization. In: Cunningham DJC, Lloyd BB (eds) The Regulation of Human Respiration. Oxford: Blackwell Scientific, 1963, 379-394.

10. Pugh LGCE The Scientific Basis of Medicine Annual Reviews, 'Man at high altitude.' 1964; 32-54.

11. Mason NP. The physiology of high altitude: an introduction to the cardio-respiratory changes occurring on ascent to altitude. Current Anaesthesia and Critical Care 2000; 11:34-41.

12. Hackett PH, Roach RC. High altitude cerebral oedema. High Alt Med Biol 2004;5:136-146.

13. Bartsch P, Mairbaurl H, Maggiorini M, Swenson ER. Physiological aspects of high-altitude pulmonary oedema. J Appl Physiol 2005; 98: 1101-1110.

14. Barker A, Maratos EC, Edmonds L, Lim E. Recurrence rates of video-assisted thoracoscopic versus open surgery in the prevention of recurrent pneumothoraces: A systematic review of randomised and non-randomised trials. Lancet 2007; 370:329-335.

15. Lippert HL, Lund O, Blegvad S, Larsen HV. Independent risk factors for cumulative recurrence rate after first spontaneous pneumothorax. Eur Respir J 1991;4:324-331.

16. Reider H. Interventions in tuberculosis control. Paris: International Union against Tuberculosis and Lung Disease; 2002.

17. Mangili A, Gendreau MA. Transmission of infectious diseases during commercial air travel. Lancet 2005; 365(9463): 989-96.
18. Robson AG, Innes JA. Problems of air travel for patients with lung disease: Clinical criteria and regulations. Breath 2006; 3(2): 141-147.

19. Dillard TA, Moores LK, Bilello KL Philips YY. The pre-flight evaluation: a comparison of the hypoxia inhalation test with hypobaric exposure. Chest 1995; 107: 352-357.

20. Dillard TA, Rosenberg AP, Berg BW. Hypoxemia during altitude exposure. A meta-analysis of chronic obstructive pulmonary disease. Chest 1993; 103: 422-425.

21. Fischer R, Lang SM, Bruckner K. Lung function in adults with cystic fibrosis at altitude: impact on air travel. Eur Respir J 2005; 25: 718-724.

22. Muhm JM, Rock PB, McMullin DL, Jones SP, Lu IL, Eilers KD, et al. Effect of aircraft-cabin altitude on passenger discomfort. New Engl J Med 2007;357:18-27.

23. Luks AM. Do lung disease patients need supplemental oxygen at high altitude? High Alt Med Biol 2009;10(4):321-327.

24. Withers A, Wilson AC, Hall GL. Air travel and the risk of hypoxia in children. Paediatric Respiratory Reviews 2011; 12(4): 271-276.

25. Luks AM. Can patients with pulmonary hypertension travel to high altitude? High Alt Med Biol 2009;10(3):215-219.

26. Dillard TA, Beninati WA, Berg BW. Air travel in patients with chronic obstructive pulmonary disease. Arch Int Med 1991;151:1793-1795.

27. Edvardsen A, Akerø A, Christensen CC, Ryg M, Skjønsberg OH. Air travel and chronic obstructive pulmonary disease: a new algorithm for pre-flight evaluation. Thorax. 2012; 67(11):964-969.

28. Nicholson TT, Sznajder JI. Fitness to fly in patients with lung disease. ANNALSATS Articles in Press. Published on 13-November-2014 as 10.1513/AnnalsATS.201406-234

29. Žugic V. Putovanje avionom bolesnika sa hroničnom opstruktivnom bolešću pluća. U: Bošnjak-Petrović V. Hronična opstruktivna bolest pluća. Beograd: Medicinski fakultet, 2011; 375-81.

30. Secommbe LM, Petres MJ. Oxygen supplementation for chronic obstructive pulmonary disease patients during air travel. Curr Opin Pulm Med. 2006;12(2):140-4.

31. Mohr LC. Hypoxia during air travel in adults with pulmonary disease. Am J Med Sci. 2008;335(1):71-9.

32. Edvardsen A, Ryg M, Akerø A, Christensen CC, Skjønsberg $\mathrm{OH}$. COPD and air travel: does hypoxia- altitude simulation testing predict in-flight respiratory symptoms? Eur Respir J. 2013; 42(5):1216-23.

33. Peterson DC, Martin-Gill C, Guyette FX, Tobias AZ, McCarthy CE, Harrington ST, et al. Outcomes of medical emergencies on commercial airline flights. N Engl J Med. 2013;368(22):2075-83. 